\title{
Pain in Chronic Pancreatitis During the COVID- 19 Lockdown: Has It Given Us a New Dimension for Treatment?
}

\author{
Kunal Parasar $^{1}$, Shantam Mohan ${ }^{2}$, Aaron G. John ${ }^{1}$, Utpal Anand ${ }^{1}$ \\ 1. Surgical Gastroenterology, All India Institute of Medical Sciences, Patna, IND 2. Gastroenterology, All India Institute \\ of Medical Sciences, Patna, IND
}

Corresponding author: Kunal Parasar, kunal.parasar@gmail.com

\section{Abstract \\ Background}

Prolonged lockdown in our country provided us with a unique opportunity to study the interplay of psychosocial impact on pain in surgically treated patients of chronic pancreatitis.

\section{Methods}

Forty-one patients who underwent surgery for chronic pancreatitis in the last 24 months were followed up, of which 27 were enrolled. The data were collected telephonically. Pain was assessed using the numeric pain rating (NPR) scale and depression using Patient Health Questionnaire (PHQ) 9. In patients having recent onset pain during the lockdown, oral tramadol $50 \mathrm{mg}$ and amitryptiline $25 \mathrm{mg}$ were prescribed and reassessed after two weeks.

\section{Results}

Of the 25 pain-free patients in February (pre-lockdown), 14 developed pain of varying intensity during the lockdown and were prescribed medications. Twelve out of 14 patients had very good resolution of pain after two weeks of medication.

\section{Conclusions}

Operated patients with chronic pancreatitis who developed new-onset depression and pain responded well to low-dose anti-depressants in addition to analgesics. This study gives indirect, objective evidence that covert depression leading to pain in chronic pancreatitis is often downplayed and interpreted as poor results of surgery.

Review began 02/11/2021 Review ended 02/13/2021 Published 02/18/2021

๑) Copyright 2021

Parasar et al. This is an open access article distributed under the terms of the Creative Commons Attribution License CC-BY 4.0., which permits unrestricted use, distribution, and reproduction in any medium, provided the original author and source are credited.
Categories: Gastroenterology, General Surgery

Keywords: chronic pancreatitis, depression, covid-19, lockdown, psycho-social

\section{Introduction}

The current coronavirus disease (COVID-19) pandemic has influenced the natural course of various diseases unrelated to the coronavirus, with numerous factors affecting it. Several countries have implemented a lockdown of varying degrees, to decrease the spread of this deadly coronavirus. The prolonged lockdown in our country provided us with a unique opportunity to study the interplay of psychosocial impact on pain in surgically treated patients of chronic pancreatitis. Recurrent epigastric pain of varying intensity and frequency is the most common presentation of chronic pancreatitis and leads to poor quality of life (QOL) in these patients [1-2]. During initial studies, the etiopathogenesis of pain was thought to be somatic and treatment centered around analgesics, but the results were consistently poor. Further research moved from somatic pain theory to the neurobiological etiology of pain [3-4]. Based on the newer theory, many other groups of medicines and interventional therapies came to the forefront but the long-term results remain poor. Even though there are recommendations for using low-dose antidepressants in any form of chronic pain, including chronic pancreatitis, objective evidence is lacking [5]. There are a few studies already published on depression in chronic pancreatitis. However, this lockdown has given a uniform psychosocial environment for the entire group of patients with chronic pancreatitis who underwent surgical intervention at our center in the last 24 months.

\section{Materials And Methods}

We prospectively analyzed our retrospectively maintained database from April 2018 to March 2020 at the department of surgical gastroenterology, All India Institute of Medical Sciences, Patna. During this period, 88 patients with chronic pancreatitis were evaluated, out of which 41 patients underwent surgery (Frey's or lateral pancreaticojejunostomy) (Table 1). 


\section{Cureus}

\section{Characteristic}

Mean age (range), years

Gender (Male/Female), n

Mean disease duration (range), months

Diarrhea, $\mathrm{n}$

Diabetes, $n$

Surgical treatment

Lateral pancreatojejunostomy

Frey's procedure $(n=31)$

$30.25(15-68)$

$22 / 9$

$41.5(2-132)$

$3(9.67 \%)$

$8(25.8 \%)$

10

21

TABLE 1: Demographic and Clinical Details of Patients

Out of 41 patients, 31 were under regular follow-up. The idea of this study was generated, as after two weeks of the implementation of lockdown, three patients operated within the last two years, who were asymptomatic before the lockdown presented to us with the complaint of pain, which was mild to moderate in intensity, dull aching, in the epigastrium and radiating to the back. We initially treated them with oral tramadol $50 \mathrm{mg}$, which was ineffective. On taking a detailed history, we were able to elicit evidence of recent onset depression due to the ongoing lockdown. So we added oral amitryptiline $25 \mathrm{mg}$ and found good results in all three patients.

This led us to plan a study, which we conducted by calling up all operated patients who have been in regular follow-up at our center and asking them about their pain status in February (pre-lockdown), in the first week of May (during the lockdown period), and then again after two weeks of medication while still being in lockdown. The pain was measured with 11 points numeric pain rating (NPR) scale. This NPR scale has been validated for various chronic pain syndromes [6]. Assessment of depression was done by PHQ 9 (Table 2) [78].

\section{$(n=27)$}

Depression as assessed with PHQ-9

Minimal (0-4)

Mild (5-9)

Moderate (10-14)

17

Moderately severe (15-19)

2

Severe (20-27)

Mean PHQ-9 score (range)

$11(3-18)$

\section{TABLE 2: PHQ-9 Patient Depression Questionnaire Responses}

PHQ-Patient Health Questionnaire

Ethical clearance was obtained. We tried calling up all 31 patients under routine follow-up but were able to contact only 27 patients.

\section{Results}

Out of the 27 patients studied, two had pain in the month of February and before the lockdown occurred, but the intensity had increased in the month of May (Figure 1). 


\section{Cureus}

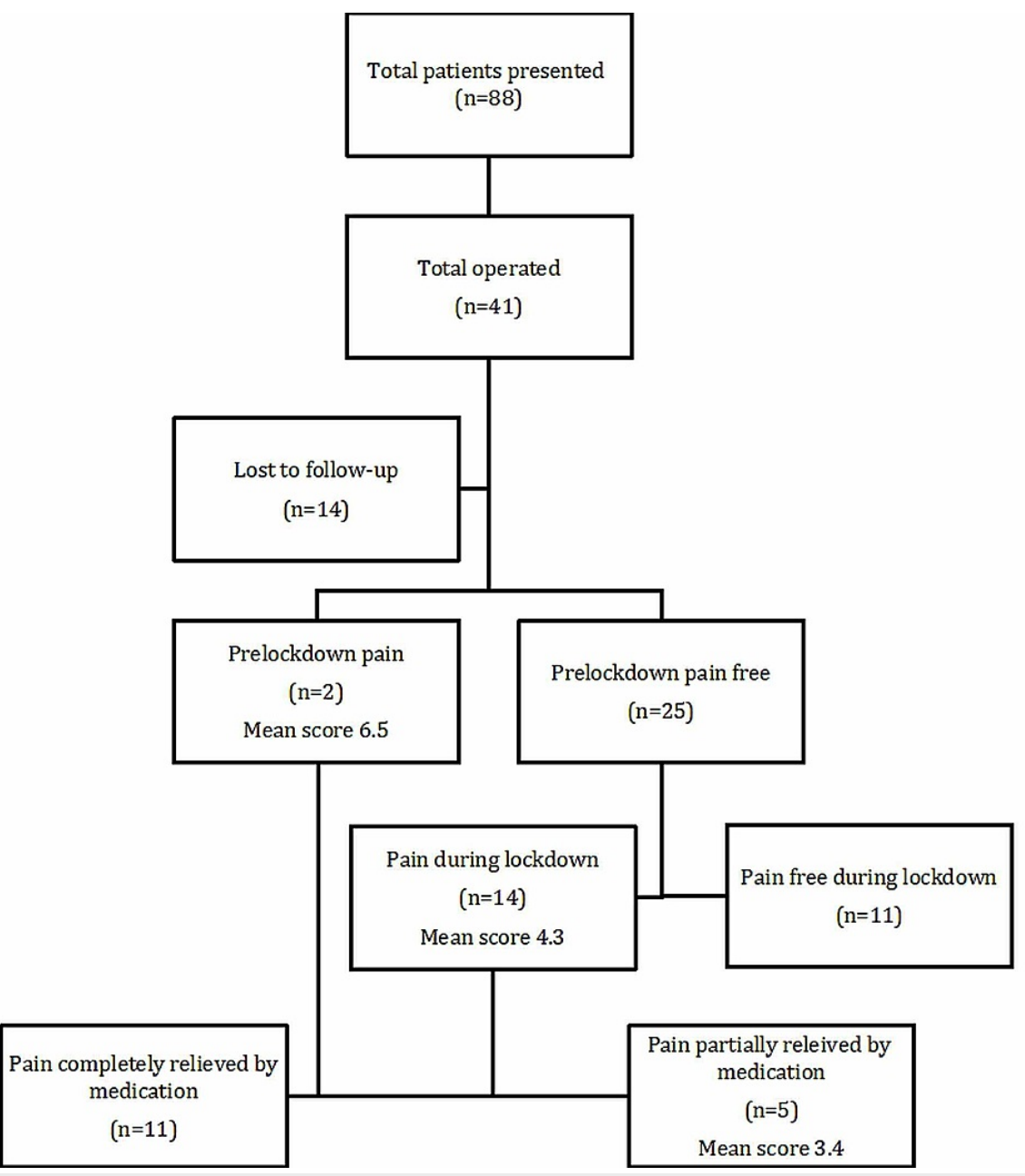

\section{FIGURE 1: CONSORT flow diagram}

CONSORT: Consolidated Standards of Reporting Trials

The rest of the 25 patients were pain-free in February (Table 3).

\begin{tabular}{|l|l|}
\hline Patients with pre-lockdown pain & (n=27) \\
\hline Patients with pain during the lockdown & 2 \\
\hline Mean pain score during the lockdown period (range) & 16 \\
\hline Pain completely relieved by medication & $4.5(3-8)$ \\
\hline Pain partially relieved by medication & $\mathbf{1 1}$ \\
\hline Mean pain score in the patients with pain (range) & 3.4 (1-5) \\
\hline
\end{tabular}

\section{TABLE 3: Characteristics of Pain as Measured by the NPR Scale}

NPR: Numeric Pain Rating

Out of the remaining 25 pain-free patients, 14 developed pain of varying intensity in the month of May. Even though the intensity of pain was variable, the nature of pain was similar in all 14 patients. We prescribed oral tramadol with amitriptyline in all 14 patients. Twelve out of 14 patients had very good resolution of pain after two weeks of medication. Three patients out of 27 had preoperative exocrine 
insufficiency and were on postoperative enzyme supplementation. None of the other 24 patients had any deterioration of exocrine insufficiency based on symptomatology. Getting data on endocrine insufficiency proved difficult, as most of them couldn't get their blood sugar examined due to the lockdown.

\section{Discussion}

Pain is the most common symptom for which patients seek treatment in chronic pancreatitis [1-2]. A ton of research has been done to elucidate the various mechanisms of pain so that therapeutic benefit could be given to patients either through medicines or through endoscopic and surgical intervention. Modern medicine has been able to alleviate pain significantly with the above-said measures. But long-term pain-free improved quality of life (QOL) is still a distant dream.

Traditionally, pancreatic ductal and parenchymal hypertension, as well as pancreatic morphological changes, were considered to be the therapeutic challenges that were dealt with by endoscopic and surgical intervention [9-13]. But the long-term results were not as expected, which forced physicians to look beyond the morphological changes. Central cortical and spinal sensitization, impaired inhibitory pain modulation, altered pancreatic nociception along with pancreatic neuropathy and neuroplasticity, increased cholecystokinin, norepinephrine, and diabetic neuropathy have all been studied as other causes of pain [1421]. Therapeutic interventions directed to all these mechanisms of pain are being tried. But the results as of now are not very encouraging [3-4].

Of all the mechanisms, depression leading to pain in chronic pancreatitis has not been studied well [22-23]. There is a very complex interplay between patient psychology and pain. The COVID-19 pandemic led to a prolonged lockdown in India, which was an unforeseen circumstance. This lockdown has allowed us to indirectly study the role of psychosomatic interplay in chronic pancreatitis pain. COVID-19, apart from its evident physical effects in infected cases, has seriously affected public mental health due to the imposition of lockdown. Different studies have pointed out an evident increase in psychological distress, depression, anxiety, and stress [24-27]. Based on this evidence and our aforementioned experiences with our cases, we surmised that psychological distress indeed might have played a role in the increase in pain in these groups of patients.

Based on telephonic conversations, covert depression of various magnitudes was present in all the patients. A noteworthy point in our study was that all the patients were surgically treated for the disease and were having good results. Still, more than $50 \%$ of our patient population, who was pain-free before lockdown, complained of typical pancreatic pain after six weeks of lockdown and got excellent results with antidepressants combined with a non-opioid analgesic.

It may be inferred that chronic pain leads to poor quality of life in patients, which, in the long term, leads to depression. This depression further propagates the pain, making it a vicious cycle. The addition of low-dose antidepressants could have helped us to break this cycle giving excellent results. It is evident from this study that the correlation between depression and pain is not linear. This study gave us indirect evidence that the mental health of patients is one of the pain pathways of pain, which we end up neglecting the most. We need further research to study this complex interplay between psychosocial aspects and pain.

The strength of our study was a very simple observational study design with an opportunity provided by circumstances. The drawback of this study is its small sample size and the indirect inference of the result. But this small study gives us an insight into a problem that deserves more attention from modern medicine.

\section{Conclusions}

Despite all the currently available therapeutic interventions, the long-term results of pain-free good quality of life is still not possible in chronic pancreatitis. One of the possible causes that has not been given due attention is covert depression associated with chronic pancreatitis. The addition of low-dose antidepressants may help break this vicious cycle of chronic pain, poor QOL, and depression and provide a good pain-free life.

\section{Additional Information}

\section{Disclosures}

Human subjects: Consent was obtained or waived by all participants in this study. Animal subjects: All authors have confirmed that this study did not involve animal subjects or tissue. Conflicts of interest: In compliance with the ICMJE uniform disclosure form, all authors declare the following: Payment/services info: All authors have declared that no financial support was received from any organization for the submitted work. Financial relationships: All authors have declared that they have no financial relationships at present or within the previous three years with any organizations that might have an interest in the submitted work. Other relationships: All authors have declared that there are no other relationships or activities that could appear to have influenced the submitted work. 


\section{References}

1. Amann ST, Yadav D, Barmada MM, et al.: Physical and mental quality of life in chronic pancreatitis: a casecontrol study from the North American Pancreatitis Study 2 cohort. Pancreas. 2013, 42:293-300. 10.1097/MPA.0b013e31826532e7

2. Mullady DK, Yadav D, Amann ST, et al.: Type of pain, pain-associated complications, quality of life, disability and resource utilisation in chronic pancreatitis: a prospective cohort study. Gut. 2011, 60:77-84. 10.1136/gut.2010.213835

3. Goulden MR: The pain of chronic pancreatitis: a persistent clinical challenge . Br J Pain. 2013, 7:8-22. $10.1177 / 2049463713479230$

4. Poulsen JL, Olesen SS, Malver LP, Frøkjær JB, Drewes AM: Pain and chronic pancreatitis: a complex interplay of multiple mechanisms. World J Gastroenterol. 2013, 19:7282-7291. 10.3748/wjg.v19.i42.7282

5. Chauhan S, Forsmark CE: Pain management in chronic pancreatitis: a treatment algorithm . Best Pract Res Clin Gastroenterol. 2010, 24:323-335. 10.1016/j.bpg.2010.03.007

6. Farrar JT, Young JP, LaMoreaux L, Werth JL, Poole RM: Clinical importance of changes in chronic pain intensity measured on an 11-point numerical pain rating scale. Pain. 2001, 94:149-158. 10.1016/S03043959(01)00349-9

7. Arroll B, Goodyear-Smith F, Crengle S, et al.: Validation of PHQ-2 and PHQ-9 to screen for major depression in the primary care population. Ann Fam Med. 2010, 8:348-353. 10.1370/afm.1139

8. Kroenke K, Spitzer RL, Williams JBW: The PHQ-9. Validity of a brief depression severity measure . J Gen Intern Med. 2001, 16:606-613. 10.1046/j.1525-1497.2001.016009606.x

9. Rösch T, Daniel S, Scholz M, et al.: Endoscopic treatment of chronic pancreatitis: a multicenter study of 1000 patients with long-term follow-up. Endoscopy. 2002, 34:765-771. 10.1055/s-2002-34256

10. Sato T, Miyashita E, Yamauchi H, Matsuno S, Yamauchi H: The role of surgical treatment for chronic pancreatitis. Ann Surg. 1986, 203:266-271. 10.1097/00000658-198603000-00008

11. Díte P, Ruzicka M, Zboril V, Novotný I: A prospective, randomized trial comparing endoscopic and surgical therapy for chronic pancreatitis. Endoscopy. 2003, 35:553-558. 10.1055/s-2003-40237

12. Bellin MD, Beilman GJ, Sutherland DE, et al.: How durable is total pancreatectomy and intraportal islet cell transplantation for treatment of chronic pancreatitis?. J Am Coll Surg. 2019, 228:329-339. 10.1016/j.jamcollsurg.2018.12.019

13. Ebbehøj N, Svendsen LB, Madsen P: Pancreatic tissue pressure: techniques and pathophysiological aspects . Scand J Gastroenterol. 1984, 19:1066-1068.

14. Friess H, Zhu ZW, di Mola FF, et al.: Nerve growth factor and its high-affinity receptor in chronic pancreatitis. Ann Surg. 1999, 230:615-624. 10.1097/00000658-199911000-00002

15. Woolf CJ, Salter MW: Neuronal plasticity: increasing the gain in pain . Science. 2000, 288:1765-1769.

16. Kuner R: Central mechanisms of pathological pain. Nat Med. 2010, 16:1258-1266. 10.1038/nm.2231

17. Ceyhan GO, Demir IE, Rauch U, et al.: Pancreatic neuropathy results in "neural remodeling" and altered pancreatic innervation in chronic pancreatitis and pancreatic cancer. Am J Gastroenterol. 2009, 104:25552565.

18. Gebhart GF: Visceral pain-peripheral sensitisation. Gut. 2000, 4:54-55. 10.1136/gut.47.suppl_4.iv54

19. Latremoliere A, Woolf CJ: Central sensitization: a generator of pain hypersensitivity by central neural plasticity. J Pain Off J Am Pain Soc. 2009, 10:895-926. 10.1016/j.jpain.2009.06.012

20. Woolf CJ: Central sensitization: Implications for the diagnosis and treatment of pain . Pain. 2011, 152:2-15 10.1016/j.pain.2010.09.030

21. Anand P, Aziz Q, Willert R, van Oudenhove L: Peripheral and central mechanisms of visceral sensitization in man. Neurogastroenterol Motil. 2007, 19:29-46. 10.1111/j.1365-2982.2006.00873.x

22. Balliet WE, Edwards-Hampton S, Borckardt JJ, et al.: Depressive symptoms, pain, and quality of life among patients with nonalcohol-related chronic pancreatitis. Pain Res Treat. 2012, 2012:978646. $10.1155 / 2012 / 978646$

23. Kuhlmann L, Olesen SS, Olesen AE, Arendt-Nielsen L, Drewes AM: Mechanism-based pain management in chronic pancreatitis - is it time for a paradigm shift?. Expert Rev Clin Pharmacol. 2019, 12:249-258. 10.1080/17512433.2019.1571409

24. Rehman U, Shahnawaz MG, Khan NH, et al.: Depression, anxiety and stress among Indians in times of Covid-19 lockdown. Community Ment Health J. 2020, 57:42-48. 10.1007/s10597-020-00664-X

25. Grover S, Sahoo S, Mehra A, et al.: Psychological impact of COVID-19 lockdown: an online survey from India. Indian J Psychiatry. 2020, 62:354-362. 10.4103/psychiatry.IndianJPsychiatry_427 20

26. Majumdar P, Biswas A, Sahu S: COVID-19 pandemic and lockdown: cause of sleep disruption, depression, somatic pain, and increased screen exposure of office workers and students of India. Chronobiol Int. 2020, 0:1-10. 10.1080/07420528.2020.1786107

27. Nilima N, Kaushik S, Tiwary B, Pandey PK: Psycho-social factors associated with the nationwide lockdown in India during COVID- 19 pandemic. Clin Epidemiol Glob Health. 2020, 9:47-52.

10.1016/j.cegh.2020.06.010 